Geopolítica(s) Revista de estudios sobre espacio y poder ISSN: 2172-3958

https://dx.doi.org/10.5209/geop.68341

\title{
El retorno de la Trampa de Tucídides: la Gran Estrategia de Estados Unidos y China frente a la disputa hegemónica desde la perspectiva de la economía política de sistemas-mundo
}

\author{
Malfred Gerig ${ }^{1}$ \\ Recibido: 14 de marzo de 2020 / Aceptado: 3 de febrero de 2021
}

Resumen. Este artículo se plantea realizar un análisis crítico de la Gran Estrategia tanto de Estados Unidos como de China ante la reorientación del centro de la economía política global a Asia oriental y el ascenso geopolítico de China. Con perspectiva histórica y global se analizan tanto las posiciones teóricas que fundamentan la Gran Estrategia de ambas potencias como la dinámica empírica de la economía política global capaz de modificar el curso de los planeamientos geoestratégicos. Para ello, en primer lugar, se realiza una crítica de los fundamentos teóricos con los que las teorías de las relaciones internacionales intentan comprender las disputas hegemónicas. En segundo lugar, se analiza cómo el espectro teórico-político de la Gran Estrategia estadounidense pretende hacer frente al reto del ascenso de China. En tercer lugar, se analiza la estrategia en política exterior de China para evitar que su ascenso genere una reacción en la potencia en declive relativo. Por último, se discuten los tres preceptos más difundidos en la literatura sobre la disputa hegemónica.

Palabras clave: Gran Estrategia; Estados Unidos; China; economía política global; geopolítica.

\section{[en] The Return of the Thucydides Trap: The Great Strategy of the United States and China in the Face of the Hegemonic Dispute from the Perspective of the Political Economy of World-Systems}

\begin{abstract}
This article tries to carry out a critical analysis of the Grand Strategy of both the United States and China in the face of the reorientation of the centre of the global political economy to East Asia and the geopolitical rise of China. From a historical and global perspective, both the theoretical positions underlying the Grand Strategy of both powers and the empirical dynamics of the global political economy capable of modifying the course of geostrategic planning are analysed. To do this, first of all, a critique of the theoretical foundations with which the theories of international relations try to understand hegemonic disputes is made. Second, it analyses how the theoretical-political spectrum of the US Grand Strategy intends to face the challenge of China's rise. Third, China's foreign policy strategy is analysed to prevent its rise from generating a reaction in the power in relative decline. Finally, the three most widespread precepts in the literature on the hegemonic dispute are discussed.
\end{abstract}

Keywords: Great strategy; United States; China; global political economy; geopolitics.

\footnotetext{
Centro Nacional de Estudios Históricos, Caracas (Venezuela).

Email: malfredgerig7@gmail.com

https://orcid.org/0000-0002-8030-9176
} 


\title{
[pt] O retorno da Armadilha de Tucídides: a Grande Estratégia de Estados Unidos e China diante da disputa hegemônica na perspectiva da economia política de sistemas-mundo
}

\begin{abstract}
Resumo. Este artigo se propõe a realizar uma análise crítica da Grande Estratégia dos Estados Unidos e da China em face da reorientação do centro da economia política global para o Leste Asiático e a ascensão geopolítica da China. Em uma perspectiva histórica e global, são analisadas as posições teóricas subjacentes à Grande Estratégia de ambas as potências e a dinâmica empírica da economia política global capaz de modificar o rumo do planejamento geoestratégico. Para tanto, é feita, em primeiro lugar, uma crítica aos fundamentos teóricos com os quais as teorias das relações internacionais buscam compreender as disputas hegemônicas. Em segundo lugar, analisa-se como o espectro teórico-político da Grande Estratégia dos EUA pretende enfrentar o desafio da ascensão da China. Terceiro, a estratégia de política externa da China é analisada para evitar que sua ascensão gere uma reação no poder em declínio relativo. Por fim, são discutidos os três preceitos mais difundidos na literatura sobre a disputa hegemônica.
\end{abstract}

Palavras-chave: grande estratégia; Estados Unidos; China; economia política global; geopolítica.

Sumario. Introducción. 1. La teoría de las transiciones hegemónicas en la economía-mundo capitalista. 2. La Gran Estrategia de Estados Unidos ante el ascenso geopolítico de China. 2.1. Brzezinski y la absorción de una China regional. 2.2. Walter Russell Mead y la contención de la China revisionista. 2.3. Mearsheimer y R. J. Art: contención y absorción en el neorrealismo. 3. China frente a la Trampa de Tucídides. 3.1. Ascenso pacifico. 3.2. La apuesta por una comunidad de destino. Comentarios finales. Agradecimientos. Referencias.

Cómo citar: Gerig, M. (2021). El retorno de la Trampa de Tucídides: la Gran Estrategia de Estados Unidos y China frente a la disputa hegemónica desde la perspectiva de la economía política de sistemasmundo. Geopolítica(s). Revista de estudios sobre espacio y poder, 12(1), 99-122. https://dx.doi.org/10.5209/geop.68341

\section{Introducción}

Un tema que ha estado usualmente confinado al debate académico especializado, el ascenso y caída de las grandes potencias, ocupó los medios de comunicación cuando el presidente de China, Xi Jinping, sostuvo que "no hay en el mundo tal cosa como la llamada trampa de Tucídides [...] Pero si los principales países cometen una y otra vez errores de cálculo estratégico, podrían crear tales trampas por sí mismos" (2015). En su Historia de la guerra del Peloponeso Tucídides (1975) adjudicó el casus belli de aquel conflicto a "que los atenienses, al haber adquirido gran preponderancia y al causar recelo a los lacedemonios, les habían forzado a hacer la guerra". A partir del pasaje del historiador griego, Graham Allison (2015) se refirió a la "Trampa de Tucídides" como a "los peligros concomitantes cuando un poder en ascenso rivaliza con un poder gobernante, como Atenas desafió a Esparta en la antigua Grecia, o como Alemania hizo con Gran Bretaña hace un siglo". Para Allison (2015) "la guerra entre los Estados Unidos y China en las próximas décadas no solo es posible, sino que es mucho más probable de lo que se reconoce en este momento".

El objetivo de este trabajo es realizar un análisis-crítico de la Gran Estrategia tanto de Estados Unidos como de China ante la reorientación del centro de la economía política global hacia Asia oriental y el ascenso geopolítico de China. Partiendo de la tesis según la cual la economía-mundo capitalista ha entrado en una disputa 
hegemónica caracterizada por "la intensificación de la competencia interestatal e interempresarial, la escalada de conflictos sociales, y el surgimiento intersticial de nuevas configuraciones de poder" (Arrighi y Silver, 2001, p.36), se cuestionan tres de los preceptos más difundidos sobre el tema: 1) que EE UU y China están destinados a una guerra global; 2) que el lugar decisivo de la disputa hegemónica es el poder militar, y 3) que China está destinada a repetir el comportamiento de otros Estados (capitalismo, territorialismo, imperialismo, euroccidentalismo) que buscaron la hegemonía.

Desde la economía política de los sistemas-mundo se adopta una perspectiva histórica y global para analizar tanto las posiciones teóricas que fundamentan la Gran Estrategia de ambas potencias como la dinámica empírica de la economía política global capaz de modificar el curso de los planeamientos geoestratégicos. Como ha sostenido Robert Gilpin, el estudio de la sociedad global tiene la urgente necesidad de integrar tanto los niveles teóricos y empíricos como "el estudio de la economía internacional con el de la política internacional para profundizar nuestra comprensión de las fuerzas que actúan en el mundo" (1990, p.13). En el siguiente apartado abordaremos desde la economía política de los sistemas-mundo, en contraposición a las teorías de las relaciones internacionales realistas y liberales, los fundamentos teóricos para comprender las disputas hegemónicas en la economía-mundo capitalista.

\section{La teoría de las transiciones hegemónicas en la economía-mundo capitalista}

En un enconado debate en 2009 entre Zbigniew Brzezinski y John J. Mearsheimer sobre las implicaciones del ascenso de China para el predominio global de EE UU, Mearsheimer resaltaba la importancia de la teoría, sosteniendo que "para predecir el futuro en Asia, se necesita una teoría que explique cómo es probable que actúen los poderes en ascenso y cómo otros Estados reaccionarán ante ellos". Brzezinski respondía arguyendo que "la teoría, al menos en las relaciones internacionales, es esencialmente retrospectiva. Cuando ocurre algo que no se ajusta a la teoría, se revisa. Y sospecho que sucederá en la relación entre Estados Unidos y China" (Brzezinski y Mearsheimer, 2009). Mientras que Mearsheimer resaltaba el poder prospectivo de la teoría, Brzezinski ubicaba el énfasis en la capacidad del dinero y las armas atómicas para producir una ruptura en las tendencias históricas. Este debate nos coloca ante lo que Zižek ha denominado una brecha de paralaje: la modificación en el objeto de estudio "causado por un cambio en la posición de observación que brinda una nueva línea de visión" (2006, p.25). La búsqueda de una perspectiva holística, sin embargo, no se produce al privilegiar una teoría en lugar de otra, sino al integrar Estados, clases, territorios y mercados en una teoría de las transiciones hegemónicas en el capitalismo histórico ${ }^{2}$.

El poder militar, la ubicación geográfica o el poder económico suelen ser el fundamento último en el que reposan las teorías de las relaciones internacionales (Kennedy, 2006, p.9). Al contrario, desde la economía política de los sistemas-mundo se sostiene que el mar de fondo en el que se mueven las relaciones en el moderno sistema interestatal devenido global es la economía-mundo capitalista, regida por la

Quedan fuera de este análisis la "teoría de la estabilidad hegemónica" (Cf. Gilpin, 1981) y la "teoría de la transición de poder" (Cf. Organski,1968). 
acumulación incesante de plusvalor, con su diferencia especifica en la "construcción del Estado y de organización de la guerra" (Arrighi, 1999, p.53; Wallerstein, 1988). $\mathrm{Al}$ adoptar esta perspectiva, surgen tres interrogantes claves.

1. ¿Qué determina la jerarquía de poder entre Estados? Mientras que para el realismo ofensivo de Mearsheimer (2001, pp.4-5) el sistema interestatal es una arena anárquica jerarquizada por la competencia militar entre grandes Estados/potencias donde el poder económico es sólo un medio, para Brzezinski la disputa territorial ha sido el gran motivo del conflicto entre Estados en la arena internacional (1998, pp.45-46). Por su parte, Skocpol (1984, p.49) se posiciona a favor de entender al Estado-nación como una unidad política, geográfica, administrativa e ideológica, que se relaciona en el sistema interestatal con otros Estados más por la competencia militar que por la dinámica del capitalismo mundial. Pese a divergir en el factor que jerarquiza a los Estados en el sistema internacional, estos autores coinciden en que los Estados-naciones son las unidades (de análisis) básicas del sistema mundial. Al contrario, para la economía política de los sistemas-mundo el criterio que jerarquiza a los Estados en el moderno sistema interestatal es el éxito en la acumulación de capital:

Los Estados han estado situados en una jerarquía de poder efectivo que no puede ser medida ni por el tamaño de sus burocracias y ejércitos ni por sus formulaciones ideológicas acerca de sí mismos, sino por su capacidad efectiva de fomentar con el tiempo la concentración de capital acumulado dentro de sus fronteras en comparación con los Estados rivales (Wallerstein, 1988, p.46).

Así, la existencia de un Estado hegemónico para la economía-mundo capitalista se encuentra en directa relación con la característica central de su forma de funcionamiento: la centralización del excedente económico entre regiones, Estados y clases (Wallerstein, 2004, p.101). La relación entre economía-mundo capitalista y moderno sistema interestatal sintetiza la dialéctica entre dominación y acumulación que se encuentra en la esencia del capitalismo histórico. Como ha argumentado Arrighi:

Un Estado puede [...] convertirse en una potencia hegemónica mundial porque puede afirmar verosímilmente que constituye la fuerza motriz de la expansión del poder colectivo de los que detentan el poder frente a los sujetos del mismo. O, a la inversa, un Estado puede convertirse en una potencia hegemónica mundial porque puede afirmar de modo verosímil que la expansión de su poder respecto a algunos o incluso todos los demás Estados es de interés general para los sujetos sometidos a la autoridad de todos los restantes Estados (1999, p.45).

Arrighi desplaza el concepto de hegemonía gramsciano de las relaciones intraestatales al sistema interestatal para poner sobre la mesa que no es sólo la capacidad de coerción la que conlleva a un Estado a dominar el sistema interestatal, sino la capacidad para reclamar un tipo de liderazgo intelectual y moral que dé direccionalidad al sistema en su conjunto. La distinción entre "Estado dominante" y "Estado hegemónico" es vital al permitir captar la especificidad del Estado capitalista en general - y el Estado líder en particular - para la economía-mundo capitalista: ser tanto la barrera que mantiene la autoridad en favor de la clase capitalista sobre las 
clases subalternas como el agente que otorga dirección de la acumulación de capital. El Estado hegemónico direcciona a todo el sistema hacia un particular modo de dominio y modo de acumulación.

2. ¿Cuál es la función del Estado hegemónico para la acumulación de capital a escala global? En la antesala de la Primera Guerra Mundial, Max Weber señalaba que "el capitalismo imperialista [...] ha ofrecido en todas las épocas las mayores probabilidades de lucro, mucho mayores que las ofrecidas normalmente por las empresas industriales exportadoras" (1964, p.676). Como coda sostenía que el "renacimiento del capitalismo 'imperialista', que ha sido siempre la característica normal del efecto producido por los intereses capitalistas sobre la política [...] no son, pues, ningún resultado del azar" (Weber, 1964, p.676). La relación entre capitalismo, territorialismo y Estado líder, el aspecto central para una teoría de las relaciones internacionales holística, ha sido un tema frecuentemente soslayado por los reduccionismos geográficos, político-institucional o militar.

En sintonía contra la tendencia del capitalismo captada por Weber, Arrighi (1999, p.49) ha contrapuesto a la lógica del poder capitalista con la lógica de poder territorialista. Por un lado, un poder que se define de acuerdo a la expansión territorial, por el otro, un poder que se expande por la obtención de los recursos necesarios para la acumulación de capital. La evidencia que arroja el análisis empírico de Arrighi identifica a la lógica capitalista con Occidente y a la lógica territorialista con Asia oriental. Los Estados occidentales han propiciado la expansión por recursos mediante la guerra en pro de la acumulación de capital a lo largo de la historia del moderno sistema-mundo, mientras que "el sistema de Estados de Asia oriental sobresalía por la práctica ausencia de competencia militar intrasistémica y de expansión geográfica extrasistémica" (Arrighi, 2007, p.329). Plantear dilemas de seguridad allende la dinámica de la acumulación de capital a escala global es una fetichización militarista de la realidad.

3. ¿Qué tipo de relación sostienen agencias capitalistas y Estados en el escenario del sistema interestatal? En la longue durée de la economía-mundo capitalista el tipo de relación entre el Estado hegemónico y las agencias empresariales líderes han determinado la diferencia especifica de los ciclos sistémicos de acumulación ${ }^{3}$. Durante la hegemonía de la Provincias Unidas la dialéctica entre mercados y Estados se realizó bajo el control del comercio de ultramar de las compañías estatutarias. Por su parte, la hegemonía de Gran Bretaña se apalancó en el imperialismo de libre comercio, mientras que la hegemonía estadounidense se efectuó a través de la corporación verticalmente integrada y el sistema de libre empresa (Arrighi, 1999; Wallerstein, 2011a, cap. 2; 2011b, cap. 2).

\footnotetext{
Un ciclo sistémico de acumulación combina una fase de expansión material con una fase de expansión financiera en la que se dibuja un siglo largo donde declina una hegemonía histórica y es sucedida por otra. Para Arrighi "pueden identificarse cuatro ciclos sistémicos de acumulación, cada uno de ellos definido por una unidad fundamental de la agencia primaria y de la estructura de los procesos de acumulación de capital a escala mundial: un ciclo genovés, que se extendió desde el siglo XV hasta principios del siglo XVII; un ciclo holandés, que duró desde finales del siglo XVI hasta finales del siglo XVIII; un ciclo británico, que abarcó la segunda mitad del siglo XVIII, todo el siglo XIX y los primeros años del siglo XX, y un ciclo americano que comenzó a finales del siglo XIX y que ha continuado hasta la fase actual de expansión financiera" (1999, p.19).
} 
En este punto es preciso señalar dos elementos claves de lo dicho para una teoría de las transiciones hegemónicas. En primer lugar, las crisis y disputas hegemónicas no se producen únicamente por la ruptura en el equilibrio de poder global, sino (sobre todo) por la aparición de una nueva organización empresarial líder con vocación universal capaz de innovar en la acumulación de capital. En segundo lugar, la transición de los ciclos sistémicos de acumulación de la fase productiva-material a la financiera acelera las tendencias competitivas a escala sistémica obligando a la deslocalización de la producción lo que termina por precipitar el conflicto hegemónico al propiciar la acumulación de capital en otra región de la economía-mundo, la cual pasa a convertirse en competidor potencial por el puesto de mando de la economía global. Esta es la forma moderna de la Trampa de Tucídides.

A diferencia de lo que sostienen los teóricos del reduccionismo militar o geográfico $^{4}$, el principal asunto para las Grandes potencias (en ejercicio o ascenso) es persistentemente la realidad capitalista:

La hegemonía de las Provincias Unidas (Países Bajos) a mediados del siglo XVII, la Gran Bretaña a mediados del siglo XIX y la de los Estados Unidos a mediados del siglo XX [...] En cada uno de los casos, la hegemonía llegó tras la derrota de un pretendiente militar a la conquista (los Habsburgo, Francia, Alemania). Cada una de las hegemonías fue sellada por una "guerra mundial" [...] de treinta años de duración, en la que intervinieron todas las potencias militares importantes de la época [...] Sin embargo, la base de la victoria no fue militar. La realidad primordial fue de carácter económico (Wallerstein, 1988, p.49).

Es la realidad económica la que pone en juicio el papel de EUA como potencia hegemónica. Luego del declive de la fase material conocida como los gloriosos treinta (1945-1968/73) expresada en la crisis de acumulación y rentabilidad (19731982) y el agotamiento de la fase financiera (1983-2007) del ciclo sistémico de acumulación estadounidense, la pregunta clave es: ¿estamos ante una disputa/transición hegemónica en el puesto de mando de la economía-mundo capitalista?

\section{La Gran Estrategia de Estados Unidos ante el ascenso geopolítico de China}

Sumergido en la reconfiguración geopolítica que significó la Guerra de Corea, George Kennan opinaba en 1951 que "cuanto menos tengamos que ver los norteamericanos con China, mejor. No hemos de anhelar los favores, ni temer la enemistad de ningún régimen chino" (citado en Anderson, 2014, p.82). Sin embargo, el giro de los acontecimientos globales no le concedió la razón a Kennan. Desde la ruptura sino-soviética, el punto clave de la Guerra Fría ${ }^{5}$, China ha sido la gran beneficiada del despliegue global de Estados Unidos. En los 22 años que trascurrieron desde el Segundo Comunicado de Shanghái (1979) al inicio de la "Guerra contra el Terror",

4 Para Brzezinski "la competencia basada en la territorialidad sigue dominando los asuntos mundiales, por más que actualmente sus formas tienden a ser más civilizadas" (1998, p.46). Para Mearsheimer, "las grandes potencias se determinan en gran medida sobre la base de su capacidad militar relativa. Para ser una gran potencia, un Estado debe tener suficientes activos militares como para emprender una lucha seria en una guerra convencional total contra el Estado más poderoso del mundo" (2001, p.5).

5 "Estratégicamente, esta división fue el acontecimiento más importante desde 1945" (Kennedy, 2006, p. 623). 
el PIB per cápita de China creció 8,2\% en promedio anual, su participación del PIB mundial pasó del 1,79\% a 4,06\% (para ascender a 15,24\% en 2017). Desde el final de la Guerra Fría a la Gran Recesión las exportaciones chinas pasaron del 1,38\% del total mundial a 7,75\% en 2008 y 10,81\% en 2017 (Banco Mundial, 2020).

De ahí que la administración Trump se expresara en una dirección más cercana a la de Spykman (Anderson, 2014, p.23) en 1942 que a la de Kennan cuando en la National Security Strategy of the United States of America (NSS) de 2017 expresara: "una competencia geopolítica entre visiones libres y represivas del orden mundial se lleva a cabo en la región del Indo-Pacífico". Además: "China presenta sus ambiciones como mutuamente beneficiosas, pero el dominio chino corre el riesgo de disminuir la soberanía de muchos Estados en el Indo-Pacífico. Los Estados de toda la región piden un liderazgo sostenido de los EE UU" (NSS, 2017, pp.45-46). El documento evidencia un desplazamiento estratégico con respecto a la administración Obama, cuyo NSS de 2015 enunciaba que "Estados Unidos celebra el surgimiento de una China estable, pacífica y próspera. Buscamos desarrollar una relación constructiva con China que genere beneficios para nuestros dos pueblos y promueva la seguridad y la prosperidad en Asia y en todo el mundo" (NSS, 2015, p.24).

Más que un simple desplazamiento en la etiqueta con que se nombra al mapa geopolítico de Asia con la sustitución del término Asia-Pacifico por Indo-Pacifico en la administración Trump (Medcalf, 2017), nos encontramos ante la puesta en acto del debate evocado por el ascenso de China en el seno de la Gran Estrategia estadounidense entre los partidarios de la contención o la absorción. El objetivo de este apartado es realizar un análisis-crítico de las posturas estratégicas suscitadas por el ascenso geopolítico de China en el espectro teórico-político de la Gran Estrategia estadounidense $^{6}$.

\subsection{Brzezinski y la absorción de una China regional}

Solo comparable en influencia sobre asuntos de política exterior de EE UU con Henry Kissinger, para Zbigniew Brzezinski la Gran Estrategia estadounidense frente al reto suscitado por China pasa por lograr una adaptación entre el ascendente poderío económico global chino y la estabilización del declive geopolítico estadounidense. Militante de la doctrina realista en la teoría de las relaciones internacionales y heredero de una prolífica tradición de geógrafos políticos europeos, Brzezinski (1998, p.39-47) sigue en la estela de la tradición al dar primacía relativa a la situación geográfica en los asuntos geopolíticos hasta considerar a Eurasia como el eje geopolítico global. No obstante, opina que el asunto geopolítico de mayor relevancia ha mutado desde que Halford Mackinder (2010) planteara su teoría del heartland gracias a que por primera vez una potencia, EE UU, posee una supremacía realmente global:

La principal cuestión geopolítica ya no es la de qué parte de la geografía de Eurasia es el punto de partida para el dominio continental, ni tampoco la cuestión de si el poder terrestre es más significativo que el poder marítimo. La geopolítica se ha

Sobre los criterios para la selección de los geo-estrategas analizados véase Kissinger (2006, cap. 2) y Anderson (2014). 
desplazado desde la dimensión regional a la dimensión global (Brzezinski, 1998, p.47).

Según el gentilhombre del imperio, EE UU fue capaz de producir un novum histórico en la geopolítica al ser la primera potencia no euroasiática en regir los asuntos euroasiáticos, ergo, ser la primera potencia realmente global. En consecuencia, la principal preocupación para la Gran Estrategia estadounidense debe ser prolongar su administración de los asuntos euroasiáticos. Para Brzezinski (1998, pp.15, 27, 29), EE UU desalojó a Europa del timón de los asuntos globales a partir de la Segunda Guerra Mundial, posición que conservaba desde el siglo XV, con ello heredó el control que los europeos habían tenido sobre el poder marítimo por 500 años para expandirlo hasta un escenario realmente global. La Guerra Fría fue entonces una batalla entre una superpotencia terrestre (bloque sino-soviético) y una superpotencia marítima (EE UU) que gracias a la capacidad persuasiva que le otorgaron las armas atómicas trasladó el campo de batalla hacia tres frentes de la periferia: Europa occidental, Asia oriental y, posteriormente, el sur de Eurasia.

La ruptura sino-soviética significó un momento decisivo para la victoria estadounidense que se sintetizó cuando la Guerra Fría acogió la forma de batalla tecnológica, conllevando al surgimiento de "la primera y única potencia realmente global" (Brzezinski 1998, p.19). En el nuevo principio de realidad post 1992 la geoestrategia imperial debía reconfigurarse para "impedir los choques entre vasallos y mantener su dependencia en términos de seguridad, mantener a los tributarios obedientes y protegidos e impedir la unión de los bárbaros" (Brzezinski, 1998, p.48).

Los Estados euroasiáticos claves en la Gran Estrategia post Guerra Fría son los sospechosos habituales: China y Rusia. En el terreno, la geoestrategia imperial diseñada por Brzezinski implicaba mantener a Europa Occidental (Francia y Alemania) bajo el resguardo político y (sobre todo) el control militar del Estado imperial. Implementar una estrategia de domesticación con los pivotes geopolíticos (Ucrania, Azerbaiyán, Corea del Sur, Turquía, Irán). Impedir ante todo una alianza sino-rusa —a la que se le pudiera sumar algún estratégico pivote, principalmente Irán-. Sin olvidar un especial cuidado para con la India (1998, pp.50, 51, 52, 53). Sobre China y Rusia la clave para EE UU es impedir una alianza estratégica entre ambos, conteniendo a uno y absorbiendo al otro. Decantándose por la contención de Rusia y la absorción de China: "China no debería ser ni contenida ni aplacada - expresaba en 1997- Debería ser tratada con respeto en su calidad de mayor Estado en desarrollo del mundo" (Brzezinski, 1998, p.200).

En 2009, tras prever la posibilidad de una alianza sino-estadunidense que asumiera a largo plazo la forma de un G2, Brzezinski mantenía su postura geoestratégica a favor de la absorción de China. Sin embargo, asimilaba el impresionante crecimiento económico del ahora indiscutible gigante asiático hasta considerarlo como la razón que impide al liderazgo chino proponerse retar el predominio global estadounidense. Brzezinski considera que la disputa por la preeminencia global se decide en el terreno militar donde "el liderazgo de China no está dispuesto a desafiar a los Estados Unidos militarmente, y su enfoque sigue siendo el desarrollo económico y la aceptación ganadora como una gran potencia" (Brzezinski y Mearsheimer, 2009). Pese a admitir la posibilidad de que China intentara expulsar a EE UU de Asia oriental para proyectarse desde un poder regional hasta alcanzar una influencia global, no concebía a mediados de la década del 2000 como esto podía suceder sin ocasionar 
un efecto boomerang que atentara contra la estabilidad del crecimiento económico chino.

En 2012 el estatuto global de China era incuestionable tras convertirse en el principal comprador de bonos de tesoro de EE UU durante la Gran Recesión. Para Brzezinski implicaba reconocer que EE UU habían fracasado en su principal tarea geopolítica en Eurasia: mantener a China con estatus regional. Ante el giro de los acontecimientos, proponía un reacomodo estratégico sin modificar sustancialmente los principales rasgos de la Gran Estrategia:

Cuando por fin se dio cuenta de que China representa una amenaza potencial a la hegemonía global de Estados Unidos mucho más peligrosa se limitó a mover las piezas en el tablero de su imaginación y a considerar que Rusia es el brazo geopolítico de un mundo occidental ampliado que conecta Europa con Japón para cercar a China, en lugar de considerar que China es el punto de apoyo de los norteamericanos en su lucha contra Rusia (Anderson, 2014, p.219).

Como asesor de la administración Obama recuperó un tópico central en su obra: la problematización de la decadencia estadounidense. Ahora desde lo que consideraba un precipitado declive global estadounidense que, sin sustituto real a corto plazo, arrojaría al sistema interestatal al caos (Brzezinski, 2012a). Una Gran Estrategia asertiva debía asentarse en la renovación interna para luego, en el terreno, liderar una expansión espacial/espiritual del mundo democrático-occidental con el fín subsumir a Turquía y Rusia. Al mismo tiempo, EE UU debe asumir el arbitraje en los asuntos asiáticos, esto es, ser tanto dinamizador económico como árbitro militar presto a sacar provecho global del conflicto regional. En resumen: erigirse como tercer beneficiado (Brzezinski, 2012b).

El análisis de Brzezinski sobresale en la literatura sobre la Gran Estrategia estadounidense al abordar la posibilidad de que China y EE UU esquiven un inevitable conflicto optando por la cooperación. Sin embargo, el reduccionismo geográfico y la matriz euroccidental en la que funda su pensamiento le impide, primero, considerar la especificidad asiática en la construcción del Estado y su impacto en el siglo XXI donde el núcleo de la economía global se está reorientando a Asia oriental (Arrighi, 2007, cap. XI; Gerig, 2019), y, segundo, valorar la importancia de la riqueza nacional para otorgar ventajas militares y geográficas cuando el tablero de juego es el sistema histórico capitalista ${ }^{7}$. Anclado a la matriz geográfica, Brzezinski cree que si China optara por retar la hegemonía global estadounidense Washington aplicaría un golpe de efecto súbito al atacar la debilidad geográfica del Reino Medio:

China es vulnerable a un posible asedio estratégico. Japón impide el acceso de China al Océano Pacífico, Rusia la separa de Europa y la India se eleva sobre un océano que lleva su nombre y que es el principal acceso de China a Oriente Medio (citado en Anderson, 2014, p.217).

"El registro histórico sugiere que a largo plazo hay una conexión muy evidente entre el ascenso y caída económicos de una gran potencia y su crecimiento y declive como poder militar importante, o imperio mundial" (Kennedy, 2006, p.20). 
Pese a que desde el fin de la Guerra Fría hasta 2017 la participación de EE UU en el total del PIB mundial, las exportaciones y la Inversión Extranjera Directa (IED) se ha reducido en 1,69\%, 2,69\% y 5,46\% respectivamente (BM, 2020), Brzezinski elige el registro meta-cultural para recentrar el debate geopolítico estadounidense hacia la decadencia interna. Incurre en la simplificación de postular como Gran Estrategia final la expansión geográfica del armonioso mundo occidental hacia Moscú y Ankara bajo la égida norteamericana mientras que el mundo oriental sucumbe a los conflictos religiosos, étnicos y geográficos de los que EE UU emergerá como juez y pacificador. Hasta el final de su vida advertiría, sin embargo, que tratar a China como un subordinado precipitaría las dificultades de EE UU para ser "preponderante" en los asuntos de Asia, minando el poder de la primera y única gran potencia realmente global (Brzezinski, 2017). Para la administración Trump estas advertencias resonaron como un eco lejano cuando la tarea de urgencia es la contención económica y militar de China.

\subsection{Walter Russell Mead y la contención de la China revisionista}

Tras la salida paulatina de la escena pública de personajes que marcaron la Gran Estrategia estadounidense desde la segunda etapa de la Guerra Fría, como Kissinger y Brzezinski, la política exterior norteamericana ha quedado abierta a una reconceptualización. Pese a la algarabía neoconservadora en los primeros compases de la "Guerra Contra el Terror" (Contreras Natera, 2011), la reflexión sobre la genuina tradición de la política exterior estadounidense realizada por Walter Russell Mead en Special Providence (2009) es el itinerario de investigación más ambicioso y con mayor impacto político en el tema desde El gran tablero mundial (1998) de Brzezinski o Diplomacia (1996) de Kissinger. El proyecto de Mead es construir una taxonomía capaz de interpretar la política exterior estadounidense desde una tradición basada exclusivamente en la historia y la doctrina de EE UU. Según Mead, la interpretación sobre los tipos de tradición en política exterior estadounidense que se impuso en los últimos compases de la Guerra Fría - la Realpolitik nixoniana de inspiración europea - soslaya a la tradición que nace a finales del siglo XIX y principios del XX y que tiene sus raíces en aspiraciones imperiales que anteceden a 1947.

Mead contrapondrá a la clásica taxonomía entre idealismo wilsoniano y realismo rooseveltiano de Kissinger (2006, cap. 2) ${ }^{8}$ una tipología de cuatro tipos que, al poner a la democracia como carta de navegación, expresan a su entender la quintaesencia del excepcionalismo estadounidense:

Se había intentado, de acuerdo con Alexander Hamilton, obtener ventajas comerciales para las empresas norteamericanas en el extranjero, siguiendo el ejemplo de Woodrow Wilson, se había asumido el deber de propagar la libertad por todo el mundo; se había observado la preocupación de Jefferson por mantener las virtudes de la república a salvo de las tentaciones extranjeras; y, al igual que Jackson, se había actuado valientemente siempre que se había desafiado el honor o la seguridad del país (Anderson, 2014, p.170).

Véase Anderson (2014: 169-183) y Van Der Pijl (2008: 143). 
Una vez asentada la taxonomía interpretativa, Mead ha procurado, en su obra y en sus posturas, realizar una síntesis que refleje los intereses de las cuatro tradiciones. No obstante, con el peso de la acumulación de capital a escala global a cuesta, las tradiciones wilsonianas, jeffersonianas y jacksonianas quedan supeditadas al avasallante impulso del hamiltonianismo.

En su cruzada contra la realpolitik de cuño europeo-continental Mead habrá de revisitar el gen capitalista de EE UU en conexión con Gran Bretaña. En su God and Gold realiza una genealogía de la identidad angloamericana conducida por "una cultura excepcionalmente proclive a las fuerzas titánicas del capitalismo" (Anderson, 2014, p.180) que tienen como leitmotiv la nunca marchita vitalidad de las finanzas. En el aspecto geoestratégico Mead coloca el énfasis, a diferencia de la obsesión euroasiática de Brzezinski, en el dominio de los océanos, cuyo control militar fue la peana del poder angloamericano desde el siglo XVI. Así las cosas, la vitalidad capitalista y el control de los océanos auguran a EE UU un futuro promisorio. Antes bien, ¿qué pasa con la rivalidad geopolítica y el reto del ascenso de China?

Según el mapa interpretativo de Mead, para 2014 el mundo se organizaba de la siguiente forma: China, Rusia e Irán son tres Estados revisionistas en ofensiva que de una $\mathrm{u}$ otra forma quieren acabar con el statu quo estadounidense surgido tras la Guerra Fría, por lo que en Asia oriental, Europa oriental y Medio Oriente la geopolítica está de regreso. Europa occidental, por su parte, permanece en un momento poshistórico gozando del resguardo militar de EE UU y lidiando con sus propios problemas económicos. En la otra acera de Occidente, Washington batalla con las consecuencias internas de las aventuras bélicas de la época de G.W. Bush al mismo tiempo que procura construir un orden mundial liberal. Para Mead (2014), Occidente recorre un momento poshistórico, América Latina no merece consideración alguna y China, Rusia e Irán se afanan por traer de regreso una historia que tiene como inexorable destino el capitalismo demo-liberal.

Sin embargo, en consonancia con la retórica de la administración Trump, en enero de 2018 expresaba que pese a los muchos desacuerdos que había entre los especialistas en geopolítica estadounidense, todo el espectro político abogaba por la contención de China: "Primero [...] Estados Unidos debe hacer mucho más para contrarrestar una China cada vez más autoritaria, mercantilista y agresiva; segundo, que la región del Indo-Pacífico es el teatro mundial más importante para los EE UU" (Mead, 2018). En el mismo lugar comparaba a la China actual con la Alemania previa a la Primera Guerra Mundial denunciando su arrogancia y proclividad a crear un frente antiestadounidense. Si China intenta ir en esa dirección, el antídoto es compartido por todo el establishment de la Gran Estrategia imperial: contener a China en Indo-Pacifico mediante una entente con India y Japón.

El credo liberal de Mead según el cual el capitalismo milenarista angloamericano avizora un futuro promisorio luce como una burda letanía ante el realismo descarnado de autores como Brzezinski. Así, la Gran Estrategia se convierte más en un manual de adoctrinamiento civil que en una doctrina geoestratégica. La arrogancia de la que Mead acusa a China es un síntoma de ese entre dos estados, entre la ataraxia y la angustia, en el que se encuentra EE UU al atravesar por un momento histórico donde se concebía insuperable al salir de la Guerra Fría y le acaeció el reto del ascenso de China.

Mead asienta el poderío geopolítico de EE UU en dos grandes mitos. Primero, supone la preeminencia del entramado financiero de Wall Street como mecanismo 
de otorgar recursos en contraposición de una China despilfarradora. Sin embargo, obvia que la financiarización en la que han incurrido los EE UU después de 1982 es siempre la expresión de agotamiento de la fase material (DM) de un ciclo sistémico de acumulación e históricamente ha traído como consecuencia "la competencia económica, los conflictos sociales, y las rivalidades interestatales hasta niveles que sobrepasan la capacidad de control del centro vigente" (Arrighi, 2007, p.245). Segundo, evocando a la primacía marítima de la doctrina de Mahan (2013) sostiene que el poder marítimo angloamericano es y seguirá siendo invencible militarmente. Si bien es cierto, por un lado, que en las anteriores transiciones hegemónicas del moderno sistema-mundo la victoria en la "guerra mundial de treinta años" fue para la potencia marítima sobre la potencia terrestre (Wallerstein, 1988, p.49), y, por el otro, que EE UU contó con una renta de protección geoestratégica por su insularidad y distancia de los focos de conflicto europeo en su encumbramiento hegemónico (Arrighi, 1999, pp.81-82). También es cierto, como sostuvo Schmitt (2001, pp.388389), que la revolución espacial y la industrialización de la guerra ocurrida en el siglo XX alteró considerablemente la relación entre el ser humano, la tierra y el mar representando un novum histórico para el ejercicio de la guerra, hasta quizá desplazar a la misma como campo final de las disputas hegemónicas.

\subsection{Mearsheimer y R. J. Art: contención y absorción en el neorrealismo}

Mientras que los liberales Mead, Ikenberry, Mandelbaum o Kupchan disfrazan tras el sentido común liberal las manidas apologías imperiales, los realistas Brzezinski, Kissinger y Kagan se esmeran en encubrir con un velo de hipocresía las intenciones imperiales del realismo ${ }^{9}$. Huyendo de esta dicotomía ha emergido como tercero excluido un tipo de teoría realista que atendiendo sobremanera a los dilemas de la seguridad se sustrae del moralizante tropo liberal. Las obras neorrealistas de John J. Mearsheimer y Robert J. Art descuellan entre la literatura sobre los conflictos en el sistema interestatal en el siglo XXI tanto por la profundidad analítica como por la serenidad en los juicios. Destacándose, en comparación, por la ausencia de apología imperial e hipostasis capitalista.

Al igual que otros realistas estructurales, para Mearsheimer los Estados son los agentes de un sistema internacional cuya dinámica, caracterizada por la anarquía, es independiente de cualquier influencia de la política interna. La anarquía definida como "ausencia de cualquier tipo de jurisdicción consensuada" (Gowan, 2002, p.44) introduce a lo interno del sistema interestatal una disputa nunca acabada por la seguridad:

Las grandes potencias se temen entre sí. Se miran con sospecha y les preocupa que la guerra pueda estar a la vista. Anticipan el peligro. Hay poco espacio para la confianza entre los Estados. Sin duda, el nivel de miedo varía a lo largo del tiempo y el espacio, pero no se puede reducir a un nivel trivial. Desde la perspectiva de

\footnotetext{
"El internacionalismo liberal es el lenguaje obligatorio del poder imperial norteamericano. El realismo, ante el riesgo de una correspondencia más estrecha con su práctica, sigue siendo facultativo y subordinado. El internacionalismo puede declararse abiertamente y alcanzar con regularidad una expresión casi pura. El realismo debe rendir tributo al internacionalismo y ofrecer articulación de ambos" (Anderson, 2014, p.205).
} 
cualquier gran potencia, todas las demás grandes potencias son enemigos potenciales (Mearsheimer, 2001, p.32).

Si el realismo defensivo deduce de la anarquía como sustrato del sistema interestatal una tendencia al equilibrio en tanto que la búsqueda de superioridad conduce a la creación de coaliciones en contra de la potencia beligerante que restauran el equilibrio de poder, para el realismo ofensivo de Mearsheimer dado que los Estados tienen como único fin su propia supervivencia "la única garantía segura de supervivencia, en un orden anárquico, es la primacía, esto es, no el equilibrio con otras potencias, sino el dominio sobre ellas" (Gowan, 2002, p.35). En el axioma de Mearsheimer, el equilibrio da pie a la incertidumbre, y siendo el objetivo último de la política exterior la supervivencia del Estado, la incertidumbre debe ser sustituida por la seguridad ofensiva. Así las cosas, la supremacía militar se des-oculta como el soporte de la política internacional y la disputa entre potencias pasa a ser, en sentido estricto, una disputa militar ${ }^{10}$.

El poder militar tiene una importancia similar en la obra de Robert J. Art. Sin embargo, las connotaciones que Art deriva del mismo sobrepasan a las de Mearsheimer. Partiendo de la consideración sobre la anarquía como sustrato de las relaciones internacionales hecha por el neorrealismo, Art (2004, p.4) se centra en denotar que la importancia del poder militar no es tanto las posibilidades que abre para la guerra sino para la diplomacia coercitiva:

La disuasión, la competencia y la defensa no son usos tácticos de la fuerza, sino resultados estratégicos, que operan entre Estados o entre Estados y actores no estatales. Estos usos no son estrictamente militares, sino de naturaleza político-militar: están destinados a cambiar el comportamiento político del Estado o del actor no estatal contra el que se dirige la fuerza (Art, 2004, p.5).

Art distingue entre política exterior y Gran Estrategia. La política exterior define una estrategia integradora del poder político, económico, militar e ideológico. La Gran Estrategia define la forma en que el poder militar fundamenta la política exterior (Art, 2004, p.2). Detrás de la retórica del interés nacional entendida como protección y seguridad, la obra de Art devela sin eufemismo el fundamento militar de la hegemonía estadounidense: "la primacía militar norteamericana [...] es el aglutinante de la interdependencia económica" (Art, citado en Anderson, 2014, p.221).

Pese a partir de posturas teóricas similares, el ascenso económico y geopolítico de China no preocupa en igual magnitud a Art que a Mearsheimer. La posición de Mearsheimer no tiene grises: "China no puede ascender pacíficamente, y, si continúa su tremendo crecimiento económico en las próximas décadas, es probable que Estados Unidos y China participen en una intensa competición de seguridad con un potencial considerable para la guerra" (Brzezinski y Mearsheimer, 2009). Por su parte, Art sostiene que:

10 "Las grandes potencias se determinan en gran medida sobre la base de su capacidad militar relativa. Para calificarse como una gran potencia, un Estado debe tener suficientes activos militares como para emprender una lucha trascendente en una guerra convencional total contra el Estado más poderoso del mundo" (Mearsheimer, 2001, p.5). 
¿Son la fricción política y las relaciones conflictivas, principalmente, e incluso la guerra, las principales cosas que estos dos poderes tienen que esperar, o también hay algunos intereses significativos compartidos? [...] Si creemos que hay elementos distintos en la relación chino-americana que difieren de las últimas diadas de potencia dominante - potencia en ascenso, entonces la triste historia de tales diadas no tiene por qué ser el futuro de ésta (2010, p.360).

En la opinión de Mearsheimer el problema de EE UU no es mantener un dominio global ya que, en los hechos, la primacía estadounidense es sólo hemisférica, sino mantener el dominio regional y "evitar que otras áreas geográficas sean dominadas por otras grandes potencias" (Brzezinski y Mearsheimer, 2009). El área geográfica neurálgica es Asia oriental, por lo que el crecimiento geopolítico de China debe expresarse en un intento de expulsión de EE UU de los asuntos asiáticos. Mientras que EE UU respondería con una estrategia de contención de China que terminaría por precipitar el conflicto (Mearsheimer, 2010, pp.389-390). El ascenso de China traerá irremediablemente un conflicto según Mearsheimer, que en primera instancia se expresará en los intentos de las potencias de controlar sus zonas geográficas y animar conflictos en "los patios traseros" del rival.

Robert J. Art (2010, p.386), en cambio, considera a China como el hegemón del Este de Asia. Pero subraya que esa preponderancia es y debe ser terrestre. Por lo que EE UU debe concentrarse en mantener su ventaja marítima relativa en el océano Pacifico. Si China lograse un desarrollo marítimo importante sólo podría expulsar a EE UU de su mar interior hacia el Océano Pacifico. En cualquier caso, China es una potencia (sólo) terrestre ${ }^{11}$. Por tanto, un conflicto con China jamás representará un peligro mayor para la seguridad de EE UU que la Guerra Fría. En estricto apego al espíritu neorrealista, que China utilice su poder económico para construir un mayor poder militar regional no es un peligro para EE UU. En resumen, la Gran Estrategia que propone Art para con China no es tanto una contención como una absorción vía proliferación militar. En el peor de los casos una nueva Guerra Fría.

Pese a que las tesis de Art y Mearsheimer sirvan para captar ciertas dinámicas sobre el comportamiento estratégico-militar de las potencias tras el ascenso de China, el árbol del reduccionismo militar les impide ver el bosque de la reorientación del centro de la economía-mundo capitalista, ya no del Viejo Mundo al Nuevo Mundo dentro del mismo hemisferio occidental, sino al Lejano Oriente. Sumergidos en la superioridad espiritual del euroccidentalismo, el relajado Art y el portador de malas noticias Mearsheimer no se preguntan por la especificidad que imprimirá a los tres grandes procesos de la disputa hegemónica, ya mencionados, que planteaban Arrighi y Silver (2001, p.36). No se cuestionan la especificidad asiática en la formación del Estado, la especificidad productiva de las empresas organizadas en redes de subcontratación por libertad de ejecución, que China tenga una población rural superior a Norteamérica, América Latina y el Caribe, Europa, Asia Central, Oriente

11 "La supremacía marítima significa que Estados Unidos puede derrotar a China en un conflicto en alta mar, mantener la libertad de las rutas marítimas en el área y proteger a las naciones insulares de la región de la coerción, ataque y conquista político-militar chino, excepto Taiwán, donde Estados Unidos puede evitar la coerción y la conquista, pero no puede frustrar un devastador ataque aéreo continental y con misiles balísticos de corto alcance" (Art, 2010, p.386). 
Medio y Norte de África juntos ${ }^{12}$, o que el contendiente por la hegemonía sea un integrante del Sur global que ocupa para 2018 el lugar 78 del ranking del PIB per cápita.

\section{China frente a la Trampa de Tucídides}

En noviembre de 2015 el presidente de China, Xi Jinping, señalaba dos trampas que su país debía procurar evitar. En el orden interno, la Trampa de ingresos medios, la cual se expresa en salarios bajos, polarización de la riqueza y estancamiento económico e impide a los países dar un salto cualitativo en el modelo de desarrollo. En el orden externo, Xi se refirió a la Trampa de Tucídides haciendo alusión a las relaciones sino-estadounidenses y la posibilidad de un conflicto bélico cuando una potencia emergente y una potencia declinante se cruzan en el sistema interestatal (Gardels, 2015). Las declaraciones de Xi se enmarcan en un contexto de debate en los círculos políticos, académicos y militares chinos sobre el tipo de relaciones internacionales que el país debe fomentar - especialmente con EE UU- para seguir el curso de vitalidad económica y ascenso pacifico (Qi Hao, 2015; Xi Jinping, 2014, cap. XII). $\mathrm{Si}$ el ascenso de China en la economía ha generado un profundo debate en la comunidad de política exterior, inteligencia, estudios estratégicos y de seguridad estadounidenses (y mundiales), en China, por su parte, ha representado un viraje estratégico de proporciones sólo comparables con su propio intento de reequilibrar su modelo de desarrollo hacia la innovación.

Nos encontramos ante un tercer momento de viraje estratégico en la política exterior de China desde la fundación de la República Popular en 1949. La política exterior de la RPCh sentó su base normativa con "Los cinco principios de coexistencia pacífica" 13 expuestos por Zhou Enlai en la Conferencia de Bandung en 1954. Cobró vitalidad propia e independencia estratégica tras la ruptura sino-soviética con la "Teoría de los Tres mundos" de Mao (1998, pp.446-454) donde se propugnaba la unión de los países del Sur Global, ajenos tanto a Washington y Moscú como a sus áreas de influencia, en medio de un sistema internacional regido por la beligerancia. Sin embargo, durante 1990 y 1991, con los sucesos de la Plaza de Tiananmén como fondo, la estrategia de China hacia el mundo sufrió un segundo viraje en el que se estableció la directriz "mantener un perfil bajo" de Deng Xiaoping (1993). En la segunda década del siglo XXI los acontecimientos globales estimularon el debate sobre la actualidad y pertinencia de la estrategia de Deng. Así, durante una visita al presidente de EE UU, Barack Obama, en 2012, Xi introduciría el concepto de "nuevo tipo de grandes relaciones de poder" (xinxing daguo guanxi) (Qi Hao, 2015; Xi Jinping, 2014, p.345).

El objetivo de este apartado es realizar un análisis-crítico de la política exterior empleada por China para conducir su ascenso geopolítico con énfasis en la transición desde la geoestrategia del "ascenso pacífico" hacia la "comunidad de destino de la humanidad".

12 Según los datos del Banco Mundial (2020) la población rural de China para 2018 era de 568.902.236 habitantes, 31.075.00 habitantes rurales menos que todas las otras regiones en conjunto.

13 "Respeto mutuo a la integridad territorial y la soberanía, no agresión recíproca, no intervención de un país en los asuntos internos del otro, igualdad y beneficio recíproco y coexistencia pacífica” (Zhou Enlai, 1998, p.138). 


\subsection{Ascenso pacifico}

Desde la III Sesión Plenaria del XI Comité Central del Partido Comunista de China (celebrado en diciembre de 1978) el crecimiento económico se convirtió en el eje central de la política, tanto interna como externa, del Reino Medio. En la década de 1990 Deng Xiaoping (1993) doblaría la apuesta por el desarrollo económico, sujetando la política exterior de China a ese objetivo con la estrategia "mantener un perfil bajo". China optaría por un rol pasivo en una dinámica internacional dominada por los EE UU y marcada por la desaparición de la URSS. La estrategia de Deng para encarar el contexto del "fin de la historia" de los 1990 le permitió al país continuar en la consecución de su objetivo fundamental con tal éxito que el crecimiento económico ocultó la debilidad geopolítica de China.

En esa década China ascendió del lugar $10(1,61 \%)$ al lugar $6(3,65 \%)$ y del lugar $19(1,19 \%)$ al lugar $9(3,31 \%)$ en el ranking global del PIB y exportaciones respectivamente (BM, 2020). El retorno de China a su posición de costumbre en la larga duración de la economía global ocasionó un febril debate sobre la "amenaza China" (China Threat) de Washington a Tokio, de Camberra a Yakarta (Roy, 1996). En 2003 Zheng Bijian - para el momento vicepresidente ejecutivo de la Escuela Central del PCCh - durante el Foro de Boao para Asia introdujo el concepto de ascenso pacífico para explicar el tipo de política exterior que China practicaría. Siendo este rápidamente utilizado por el premier Wen Jiabao y el presidente Hu Jintao a partir de 2004.

La estrategia de ascenso pacifico desarrollada por Zheng, utilizada en la administración Hu-Wen como "desarrollo pacífico", consistía en un reacomodo de la doctrina de Deng "mantener un perfil bajo" en un contexto en el que China no podía esconder su crecimiento económico, dados los marcados signos de la reorientación del centro de la economía global hacia Asia oriental con China como núcleo. Así, explicaba Zheng (2005) las tensiones por resolver:

Entre el alto crecimiento del PIB y el progreso social, entre mejorar la tecnología y aumentar las oportunidades laborales, entre mantener el impulso del desarrollo en las zonas costeras y acelerar el desarrollo en el interior, entre fomentar la urbanización y nutrir las áreas agrícolas, reducir la brecha entre ricos y pobres y mantener la vitalidad y eficiencia económica, atraer más inversión extranjera y mejorar la competitividad de las empresas indígenas, profundizar las reformas y preservar la estabilidad social [...] La primera estrategia es trascender el viejo modelo de industrialización y avanzar uno nuevo [...] China está decidida a forjar un nuevo camino de industrialización basado en la tecnología, la eficiencia económica, el bajo consumo de recursos naturales en relación con el tamaño de su población, la baja contaminación ambiental y la asignación óptima de recursos humanos. [...] La segunda estrategia es trascender las formas tradicionales en que emergen las grandes potencias, así como la mentalidad de la Guerra Fría que definió las relaciones internacionales a lo largo de líneas ideológicas. China no seguirá el camino de Alemania hasta la Primera Guerra Mundial o los de Alemania y Japón previos a la Segunda Guerra Mundial, cuando estos países saquearon violentamente los recursos y persiguieron la hegemonía. Tampoco China seguirá el camino de las grandes potencias que compiten por la dominación mundial durante la Guerra Fría. 
En cambio, China trascenderá las diferencias ideológicas para luchar por la paz, el desarrollo y la cooperación con todos los países del mundo.

La estrategia de ascenso pacífico diseña la política exterior que guiará la transición china de semiperiferia manufacturera - que ha recuperado, por la vía de la industrialización para la exportación, el rol histórico ejercido como atractor de los medios de pago mundiales (Frank, 2008, cap. 3) - hacia el centro de la división internacional del trabajo, en tanto que es en el sistema interestatal donde se sintetiza la relación entre gobiernos, territorios y mercados. Más que producirse un reacomodo tectónico de la política exterior, la estrategia de ascenso pacífico conservaba al crecimiento económico como el logro más alto para la política china procurando introducir vitalidad en un momento en que el sistema interestatal exigía un papel más dinámico del Beijing en los asuntos globales.

Ahora bien, la búsqueda del ascenso pacífico de Beijing debe ser interpretada a partir de la sugerente tesis de Arrighi (2007, pp.274-326) según la cual China ha sido el gran triunfador de la "Guerra con el Terror" llevada a cabo por EE UU tras el 11 de septiembre de 2001. Entre el inicio de la "Guerra contra el Terror" y el estallido de la Gran Recesión en Occidente con la crisis de las hipotecas subprime el PIB chino creció en 10,67\% anual en promedio mientras que la Unión Europea (UE) y los EE UU lo hicieron en 2,01\% y 2,11\%, por su parte, el gasto militar de China (como porcentaje del PIB) fue de 1,97\%, más parecido al de la "protegida" UE que al de Rusia (3,3\%) o EE UU (7,2\%) (BM, 2020). De ahí que Arrighi se pregunte:

\begin{abstract}
¿No sería acaso la mejor estrategia de poder por parte de China frente a Estados Unidos una variante de la estrategia anterior de Estados Unidos frente a Gran Bretaña? ¿No sería lo mejor para China, uno, dejar que Estados Unidos se agotara militar y financieramente en una guerra contra el terror sin fin a la vista; dos, enriquecerse suministrando productos y crédito a la superpotencia estadounidense, cada vez más incoherente; y tres, utilizar su riqueza y su mercado interno en expansión para ganarse aliados (incluidas algunas empresas estadounidenses) en la creación de un nuevo orden mundial centrado en China, pero no necesariamente dominado militarmente por China? (2007, p.326).
\end{abstract}

Así como en el aspecto económico la estrategia de China ante la Gran Recesión fue comprar con sus ingentes reservas a través de los bonos del tesoro la estabilidad sistémica que le permitiera producir un reequilibrio de su economía en armonía con la reorientación del centro de la economía-mundo capitalista (Gerig, 2019), en el aspecto geopolítico China emprendió una estrategia tertius gaudens otorgando estabilidad económica para que EE UU se desgastara en el reacomodo del mapa político de Oriente Medio (Contreras Natera, 2011) e intentara, reavivando la obsesión por el Heartland, llevar a la OTAN a Kiev (Anderson, 2017) mientras Beijing continuaba con la senda de crecimiento pacífico y acumulaba fuerzas para recrear a escala global el sistema comercial tributario centrado en China (Arrighi, 2007, cap. XI).

En la década de 2010 ya no era una posibilidad para China mantener un perfil bajo, ya que se convirtió en la segunda economía por tamaño del PIB, el principal exportador global y salió al rescate del dólar en la Gran Recesión. Yan Xuetong (2014, p.161) expresaba recelos ante la eficacia de la estrategia de mantener un perfil bajo en la nueva dinámica global: "Durante 1992-2011, la participación de China en 
el comercio mundial aumentó del $0,02 \%$ al $10 \%$, pero las relaciones de China con el resto del mundo no experimentaron mejoras sustanciales". Agregando que "el ambiente favorable para el desarrollo económico no trajo a China más amigos ni ayudó a China a construir una buena imagen global".

\subsection{La apuesta por una comunidad de destino}

Desde que Xi Jinping asumiera como presidente de la RPCh en 2013 hasta el XIX Congreso del PCCh en 2017, donde el país adoptara el socialismo con características chinas para la nueva época, la política exterior del gigante asiático ha dado un vuelco tectónico. En la Conferencia de Asuntos Exteriores del PCCh del 24 de octubre de 2013 Xi propone el concepto de "luchando por el logro" (fenfa youwei) como reemplazante de la estrategia "mantener un perfil bajo" de Deng (Yan Xuetong, 2014, p.154). En la nueva época la política exterior estará activamente guiada al cumplimiento del "objetivo de los dos centenarios": 1) construir una sociedad "modestamente acomodada" para el centenario del PCCh en 2021; 2) convertir a China en un país "socialista moderno" para 2049. Para ello el liderazgo chino transita de la geoestrategia de ascenso pacífico a la comunidad de destino de la humanidad.

Discursivamente, la estrategia "luchar por el logro" expresa el deseo de "un nuevo tipo de relaciones internacionales basadas en el respeto mutuo, la equidad y la justicia, y la cooperación y el ganar-ganar", mientras que en el núcleo estratégico se señala sin ambages: "nuestro país aplica una política de defensa nacional de carácter defensivo. Su desarrollo no supone amenaza alguna para ningún país. Y China jamás aspirará a la hegemonía ni practicará la expansión, sea cual sea su grado de desarrollo" (Xi Jinping, 2017). La estrategia busca que China ejerza un rol dinamizador en el sistema interestatal con la intención de construir una nueva gobernanza global allende al unilateralismo estadounidense. Además, la comunidad de destino de la humanidad recupera la vocación del universalismo concreto de la política exterior china ausente desde tiempos de Mao cuyo hito es la Conferencia de Bandung.

La nueva estrategia trata de hacer mayor hincapié en los factores geopolíticos reconciliándolos con la orientación geoeconómica. Para un entusiasta de la nueva orientación como Yan Xuetong:

A diferencia del KLP con un valor central de beneficios económicos, la SFA le da prioridad a la dignidad política sobre los intereses económicos. En aras de la dignidad, la SFA establece la tarea de hacer amigos como el objetivo más importante de la política exterior china ${ }^{14}$ (2014, p.182).

Esta es la manera con la que China está reaccionando al viraje estratégico de Washington hacia Beijing producido en la segunda administración Obama al intentar reequilibrar Asia-Pacífico ante el auge de China (Anderson, 2014, p.154). Si bien la política de Obama priorizaba el enfoque multilateral teniendo como núcleo el comercio, mientras que la estrategia Indo-Pacífico de la administración Trump privilegia el enfoque unilateral, en ambos casos se denota que la principal preocupación de Washington en los hechos es la competencia china. Como contrapartida, China está dispuesta a que sus vecinos se beneficien de su crecimiento económico y de los

14 Con SFA se refiere a "lucha por el logro" y con KLP "mantener un perfil bajo". 
medios de pago universalmente aceptados que acumula si esto es capaz de otorgarle credibilidad moral en el escenario internacional. Tras aceptar la tesis realista por excelencia de que un poder en ascenso como China seguramente desafiará al país hegemónico e introducirá temores en la comunidad circundante, Yan Xuetong sostiene:

El liderazgo político de la autoridad humana considera la credibilidad estratégica como la base de la autoridad internacional, por lo tanto, considera la credibilidad estratégica como el interés nacional más importante. La estrategia de SFA adoptada por Xi Jinping apunta a aumentar la credibilidad estratégica de China, que incluye proporcionar protección de seguridad para los vecinos. El realismo moral considera la cooperación de seguridad como la base para relaciones estratégicas confiables entre la potencia en ascenso y otras naciones porque solo la cooperación de seguridad puede reducir el miedo de los vecinos, aumentar la dependencia de los pequeños Estados y ganar más apoyo estratégico (2014, p.182).

Pese a partir de posturas teóricas diversas, la tesis de Xuetong se adhiere a la distinción entre hegemonía y dominación que Arrighi (1999) introduce para el sistema interestatal a partir de Gramsci. A diferencia de otras potencias en ascenso en la longue durée del moderno sistema-mundo China puede utilizar su posición económica para atraer a vecinos, que en otra circunstancia caerían en stress estructural tras el inminente ascenso económico del Reino Medio. Una voz autorizada como Yang Jiechi (2018) explica la estrategia sin reservas: "China integrará estrechamente la Iniciativa Belt and Road con la construcción de una comunidad con un futuro compartido para la humanidad y el cumplimiento de la Agenda 2030 para el Desarrollo Sostenible a fin de construir una nueva plataforma para la cooperación internacional". El viraje de la Gran Estrategia china da cuenta que ha terminado el periodo geopolítico en el que podía ocultar su ascenso ante EE UU al este encontrarse empantanado en la "Guerra Contra el Terror", por tanto, China busca poseer un rol más activo en el sistema interestatal al potenciar su poder militar defensivo ${ }^{15}$, colocar el poder económico al servicio de la política exterior $-\mathrm{y}$ no al revés - $\mathrm{y}$ fomentar un liderazgo moral que se distancie del unilateralismo estadounidense.

La expansión de la economía-mundo europea desde el largo siglo XVI ha producido también la expansión del moderno sistema interestatal de cuño westfaliano con sus características competencia militar y expansión territorial (Arrighi, 2007, pp.329-330). En el ocaso del largo siglo XX esas dinámicas europeas han devenido globales. Asia oriental fue la última macro-región en ser absorbida por la dinámica del moderno sistema-mundial durante el siglo XIX (Wallerstein, 2001, p.42). No obstante, "si a finales del siglo XIX y principios del XX la convergencia se produjo principalmente desde Asia oriental hacia la vía occidental [...] durante la segunda mitad del siglo XX le tocó a la vía occidental converger hacia la de Asia oriental" (Arrighi, 2007, p.357). Por lo que el proyecto de comunidad de destino para la humanidad de Xi parece una actualización y expansión a escala global de lo que el historiador japonés Takeshi Hamashita ha denominado el sistema comercial tributario centrado en China en el que:

$15 C f$. Estrategia militar de China (2015). 
Las regiones, países y ciudades localizadas a lo largo del perímetro de las varias zonas costeras que se extienden desde nordeste hasta el sudeste de Asia estaban lo bastante próximas para influirse mutuamente, pero también bastante alejadas como para asimilar unas a otras o ser asimiladas. El sistema tributario-comercial sinocéntrico proporcionó a estas entidades territoriales un marco político y económico de integración mutua (Arrighi y Silver, 2001, p.252).

\section{Comentarios finales}

La tesis que ha conducido nuestro análisis es que la economía-mundo capitalista ha entrado en un periodo de conflicto hegemónico. Hemos situado nuestro objetivo en entender cómo la Gran Estrategia en EE UU y China prevé los escenarios (hipotéticos o en marcha) de la disputa centrándonos en la "configuración de nuevas relaciones de poder" a escala global (Arrighi y Silver, 2001, p.36). En primer lugar, se realizó una crítica a los fundamentos teóricos con los que las teorías de las relaciones internacionales intentan comprender las disputas hegemónicas expresando la necesidad de integrar holísticamente Estados, clases, territorios y mercados. En segundo lugar, se analizó cómo el espectro teórico-político de la Gran Estrategia estadounidense - de liberales a conservadores, de realistas a idealistas y neorrealistas - pretende hacer frente a la reorientación del centro de la economía política global hacia Asia oriental y el ascenso de China centrándonos en las estrategias de absorción y contención. En tercer lugar, analizamos la estrategia en política exterior de China para prever que su ascenso genere una reacción en la potencia en declive relativo que active la Trampa de Tucídides. Por último, expondremos algunas consideraciones sobre los tres preceptos más difundidos en la literatura sobre la disputa sino-estadounidense señalados en la introducción.

1. ¿Están destinados EE UU y China a una guerra global? La obsesión de la Gran Estrategia estadounidense por tratar de situar la disputa en el plano militar más que un análisis estricto de las probabilidades tomando en cuenta la evidencia histórica, es un intento de enfocar prospectivamente el conflicto hacia el campo de batalla donde EE UU cuenta con una superioridad inobjetable. Protegidos por su ventaja militar, el acceso a los océanos Atlántico y Pacífico y sentados en el puesto de mando de las altas finanzas globales Washington, sin duda, prefería que Beijing repita la fórmula de ascenso para enfrentarse a la hegemonía británica utilizada por Alemania en el siglo XX, y no la fórmula empleada por los mismos EE UU cuando en lugar de desafiar militarmente a Gran Bretaña o Alemania optaron por alejarse de la conflagración europea, convertirse en el prestamista por excelencia de la potencia en declive relativo e intervenir en el conflicto bélico no para ganar la guerra sino para dictaminar los términos de la paz (Arrighi, 2007, p.326).

2. ¿Es el poder militar el lugar decisivo de la disputa hegemónica? Como se ha señalado anteriormente, pese a que todas las hegemonías en el sistema-mundo moderno llegaron tras una gran guerra de treinta años el fundamento de los vencedores no fue militar sino económico (Wallerstein, 1988, p.49; Kennedy, 2006, p.21). La competencia militar por el equilibrio de poder ha sido un componente central del enmarque westfaliano del moderno sistema interestatal. Sin embargo, el surgimiento 
de las armas nucleares (1945) y la destrucción mutua garantizada ha cambiado las reglas del juego político-militar entre grandes potencias abriendo el campo de la diplomacia coercitiva. De ahí que, el principio de realidad militar en un mundo gobernado por potencias nucleares sea la combinación de Guerra Fría en el centro con "guerras calientes" a pequeña escala en la periferia.

La preeminencia del poder militar ha venido trayendo graves consecuencias para EE UU en tanto que, consciente de su decadencia económica, trata de apalancarse en él. Sin embargo, como ha señalado Kennedy (2006, p.22), "las grandes potencias en decadencia relativa responden instintivamente gastando más en 'seguridad', y por lo tanto desvían recursos potenciales del terreno de la 'inversión' y agravan su dilema a largo plazo".

3. ¿Está China destinada a repetir el comportamiento de otros Estados (capitalismo, territorialismo, imperialismo, euroccidentalismo) que buscaron la hegemonía? El arúspice del ascenso y caída de las hegemonías en el sistema mundo moderno debe ser lo suficientemente flexible como para, partiendo siempre de la experiencia histórica, dar cabida a cambios drásticos en las tendencias y comportamientos. Por lo que, si el objetivo es inferir el comportamiento de China en lo que respecta al capitalismo, territorialismo, imperialismo e euroccidentalismo los caminos epistemológicos a seguir son tanto la larga duración como la dinámica empírica de su ascenso en la coyuntura histórica.

En una crítica a la estrategia de contención de EE UU para con China, Kissinger (2005) sostenía que "el imperialismo militar no es el estilo chino". Luego agregaba: "China busca sus objetivos mediante un estudio cuidadoso, paciencia y la acumulación de matices. Rara vez China se arriesga a un enfrentamiento donde el ganador se lo lleva todo". En el largo siglo XIX convergieron Occidente y Oriente, el moderno sistema interestatal y el sistema tributario centrado en China, la economía-mundo capitalista de cuño europeo con la economía de mercado no-capitalista de Asia oriental. En el largo siglo XX Asia oriental fue periferizada, y su particularidad en la organización del mercado, construcción del Estado y disposición a la guerra fue subsumida a la senda de desarrollo occidental. En la coyuntura histórica en la que se imbrican el fin del largo siglo XX y el comienzo del largo siglo XXI está dando lugar a una Gran Convergencia entre Oriente y Occidente. ¿Podrá China reorientarse hacia la historia de Asia oriental o continuará el dominio de la senda de desarrollo occidental sobre la economía-mundo capitalista?

\section{Agradecimientos}

Agradezco a Miguel Ángel Contreras Natera y Juan Antonio Hernández por los debates y sugerencias sobre la temática.

\section{Referencias}

Allison, G. (2015). The Thucydides Trap: Are the U.S. and China Headed for War? The Atlantic, 25 de septiembre. Recuperado de https:/www.theatlantic.com/international/archive/2015/09/united-states-china-war-thucydides-trap/406756/ 
Anderson, P. (2014). Imperium et Consilium: la política exterior norteamericana y sus teóricos. Madrid: Akal.

Anderson, P. (2017). Pasando el bastón de mando. New Left Review, (103), 43-68. Recuperado de https://newleftreview.es/issues/103/articles/perry-anderson-pasando-el-bastonde-mando.pdf

Arrighi, G. (1999). El largo siglo XX: dinero y poder en los orígenes de nuestra época. Madrid: Akal.

Arrighi, G. (2007). Adam Smith en Pekín: orígenes y fundamentos del siglo XXI. Madrid: Akal.

Arrighi, G. y Silver, B. J. (2001). Caos y orden en el sistema-mundo moderno. Madrid: Akal. Art, R. J. (2004). A Grand Strategy for America. Ithaca: Cornell University Press.

Art, R. J. (2010). The United States and the Rise of China: Implications for the Long Haul. Political Science Quarterly, 125(3), 359-391.

Banco Mundial (BM) (2020). Datos de libre acceso del Banco Mundial. Recuperado de https://datos.bancomundial.org/

Brzezinski, Z. (1998). El gran tablero mundial: la supremacía estadounidense y sus imperativos geoestratégicos. Barcelona: Paidós.

Brzezinski, Z. (2012a). After América. Foreign Policy, 3 de enero. Recuperado de http://foreignpolicy.com/2012/01/03/after-america/

Brzezinski, Z. (2012b). Balancing the East, Upgrading the West: U.S. Grand Strategy in an Age of Upheaval. Foreign Affairs, 91(1). Recuperado de https://www.foreignaffairs.com/articles/2011-12-13/balancing-east-upgrading-west

Brzezinski, Z., y Mearsheimer, J. J. (2015). Clash of Titans. Foreign Policy, (146). Recuperado de http://foreignpolicy.com/2009/10/22/clash-of-the-titans/

Brzezinski, Z. y Wasserman, P. (2017). Why the World Needs a Trump Doctrine. The New York Times, 20 de febrero. Recuperado de https:/www.nytimes.com/2017/02/20/opinion/why-the-world-needs-a-trump-doctrine.html

Contreras Natera, M. Á. (2011). Una geopolitica del espíritu. Leo Strauss: la filosofía política como retorno y el imperialismo estadounidense. Caracas: Celarg.

Deng Xiaoping (1993). Textos escogidos de Deng Xiaoping (1982-1992) (t. III). Beijing: Editorial del Pueblo.

Estrategia militar de China (2015). Beijing: Ediciones en Lenguas Extranjeras.

Frank, A. G. (2008). Re-Orientar: la economía global en la era del predominio asiático. Valencia: Publicaciones de la Universidad de Valencia.

Gardels, N. (2015). Chinese President Xi Jinping Meets the 21st Century Council in Beijing. Berggruen Institute, 3 de noviembre. Recuperado de https://www.berggruen.org/activity/chinese-president-xi-jinping-meets-the-21st-century-council-in-beijing/

Gerig, M. (2019). Marx en Shanghái, Schumpeter en Shenzhen: el reequilibrio de la economía china y la reorientación de la economía política global. Cuadernos De Economía Crítica, 6(11), 65-89. Recuperado de http://sociedadeconomiacritica.org/ojs/index.php/cec/article/view/160

Gilpin, R. (1981). War and Change In World Politics. New York: Cambridge University Press.

Gilpin, R. (1990). La economía politica de las relaciones internacionales. Buenos Aires: Grupo Editor Latinoamericano.

Gowan, P. (2002). Un cálculo de poder. New Left Review, (16), 44-63. Recuperado de https://newleftreview.es/issues/16/articles/peter-gowan-un-calculo-de-poder.pdf 
Kennedy, P. (2006). Auge y caída de las grandes potencias. Barcelona: Debolsillo.

Kissinger, H. (2005). China: Containment won't Work. The Washington Post, 13 de junio. Recuperado de https://www.henryakissinger.com/articles/china-containment-wontwork/

Kissinger, H. (2006). Diplomacia. Barcelona: Ediciones B.

Mackinder, H. J. (2010). El pivote geográfico de la historia. Geopolitica(s). Revista de estudios sobre espacio y poder, 1(2), 301-319.

Mahan, A. T. (2013). Análisis de los elementos del poder naval. Geopolitica(s). Revista de estudios sobre espacio y poder, 4(2), 305-334.

Mao Zedong. (1998). Mao Zedong on Diplomacy. Beijing: Foreign Languages Press.

Mead, W. R. (2009). Special Providence: American Foreign Policy and How it Changed the World. New York: Routledge.

Mead, W. R. (2014). The Return of Geopolitics: The Revenge of the Revisionist Powers. Foreign Affairs, 93(3). Recuperado de https:/www.foreignaffairs.com/articles/china/2014-04-17/return-geopolitics

Mead, W. R. (2018). Left and Right Agree: Get Tough on China. The Wall Street Journal, 8 de enero. Recuperado de https://www.wsj.com/articles/left-and-right-agree-get-toughon-china-1515458432

Mearsheimer, J. J. (2001). The Tragedy of Great Power politics. New York: W.W Norton \& Company.

Mearsheimer, J. J. (2010). The Gathering Storm: China's Challenge to US Power in Asia. The Chinese Journal of International Politics, 3(4) 381-396 https://doi.org/10.1093/cjip/poq016

Medcalf, R. (2017). Goodbye Asia-Pacific. But why the sudden buzz over Indo-Pacific. South China Morning Post, 31 de diciembre. Recuperado de http://www.scmp.com/week-asia/geopolitics/article/2126210/goodbye-asia-pacific-whysudden-buzz-over-indo-pacific

National Security Strategy of the United States of America (NSS) (2017). Recuperado de https://trumpwhitehouse.archives.gov/wp-content/uploads/2017/12/NSS-Final-12-182017-0905-2.pdf

National Security Strategy of the United States of America (NSS) (2015). Recuperado de https://obamawhitehouse.archives.gov/sites/default/files/docs/2015_national_security_strategy_2.pdf

Organski, A. F. K. (1968). World Politics. New York: Alfred A. Knopf.

Qi Hao. (2015). China Debates the "New Type of Great Power Relations". The Chinese Journal of International Politics, 8(4), 349-370. https://doi.org/10.1093/cjip/pov012

Roy, D. (1996). The “China Threat” Issue: Major Arguments. Asian Survey, 36(8), 758-771. https://doi.org/10.2307/2645437

Schmitt, C. (2001). Tierra y Mar: consideraciones sobre la historia universal. En H. Orestes Aguilar (Comp.), Carl Schmitt, teólogo de la política (pp.345-389). México: Fondo de Cultura Económica.

Skocpol, T. (1984). Los Estados y las revoluciones sociales: un análisis comparativo de Francia, Rusia y China. México: Fondo de Cultura Económica.

Tucídides (1975). Historia de la guerra del Peloponeso. Barcelona: Juventud.

Van Der Pij1, K. (2008). Ideologías atlánticas. New Left Review, 50, 141-149. Recuperado de https://newleftreview.es/issues/50/articles/kees-van-der-pijl-ideologias-atlanticas.pdf

Wallerstein, I. (1988). El capitalismo histórico. México: Siglo XXI. 
Wallerstein, I. (2001). Conocer el mundo, saber el mundo: el fin de lo aprendido. Una ciencia social para el siglo XXI. México: Siglo XXI.

Wallerstein, I. (2004). El ascenso y futura decadencia del sistema-mundo capitalista: conceptos para un análisis comparativo. En I. Wallerstein, Capitalismo histórico y movimientos antisistémicos (pp. 85-114). Madrid: Akal.

Wallerstein, I. (2011a). El moderno sistema mundial, Vol. II: el mercantilismo y la consolidación de la economía-mundo europea, 1600-1750 (2da. ed.). México: Siglo XXI.

Wallerstein, I. (2011b). El moderno sistema mundial, Vol. III: la segunda era de gran expansión de la economía-mundo capitalista, 1730-1850 (2da. ed.). México: Siglo XXI.

Weber, M. (1964). Economía y sociedad: esbozo de sociología comprensiva (2da ed.). México: Fondo de Cultura Económica.

Xi Jinping. (2014). La gobernación y administración de China. Beijing: Ediciones en Lenguas Extranjeras.

Xi Jinping. (2015). Speech on China-U.S. relations at a welcoming dinner in Seattle. Chinadaily, 22 de septiembre. Recuperado de https://www.chinadaily.com.cn/world/2015xivisitus/2015-09/24/content_21964069_3.htm

Xi Jinping. (2017). Informe presentado por Xi Jinping ante XIX Congreso Nacional del PCCh. Xinhua, 3 de noviembre. Recuperado de http://spanish.xinhuanet.com/201711/03/c 136726335.htm

Yan Jiechi. (2018). The 19th CPC National Congress and China's Major Country Diplomacy in the New Era. QiuShi Journal, 10(1). Recuperado de http://english.qstheory.cn/201802/11/c_1122395899.htm

Yan Xuetong. (2014). From Keeping a Low Profile to Striving for Achievement. The Chinese Journal of International Politics, 7(2), 153-184. https://doi.org/10.1093/cjip/pou027

Zheng Bijian. (2005). China's "Peaceful Rise" to Great-Power Status. Foreign Affairs, 84(5). Recuperado de https://www.foreignaffairs.com/articles/asia/2005-09-01/chinaspeaceful-rise-great-power-status

Zhou Enlai. (1998). Obras escogidas de Zhou Enlai: tomo II. Beijing: Ediciones en Lenguas Extranjeras.

Žižek, S. (2006). Visión de paralaje. Buenos Aires: Fondo de Cultura Económica. 